\title{
CONTROLE MÚLTIPLO NO COMPORTAMENTO VERBAL: HUMOR BRASILEIRO E OPERANTES RELACIONADOS
}

\section{MULTIPLE CONTROL IN VERBAL BEHAVIOR: BRAZILIAN HUMOR AND RELATED OPERANTS}

\author{
Maria Martha Costa Hübner ${ }^{1}$ \\ UNIVERSIDADE DE SÃO PAULO, BRASIL
}

Caio Flávio Miguel

WESTERN MICHIGAN UNIVERSITY, UNITED STATES

JACK MiCHAEL

WESTERN MICHIGAN UNIVERSITY, UNITED STATES

\begin{abstract}
RESUMO
O presente texto apresenta a formulação de Skinner (1957) a respeito das variáveis responsáveis por aquilo que é compreendido como humor, com exemplos relacionados à literatura e cultura brasileiras. O comportamento responsável por produzir efeitos humorísticos sobre o ouvinte é entendido como sendo passível de controle múltiplo. Esse comportamento é analisado através de seus produtos, como textos e amostras de linguagem falada, sendo possível fazer inferências a respeito das condições nas quais o comportamento ocorreu. Trocadilhos e piadas são exemplos de controle múltiplo dado que: 1) a força de uma determinada resposta é função de mais de uma variável, uma forma de controle múltiplo convergente; 2) uma única variável geralmente afeta mais de uma resposta, uma forma de controle múltiplo divergente. O controle múltiplo pode envolver uma palavra ou frase que está sob controle de pelo menos duas variáveis, ou "fontes" a mesmo tempo. A palavra ou frase é denominada resposta crítica e as variáveis controladoras são consideradas fontes temáticas principais, fontes secundárias e fontes transportadoras. Através de diferentes exemplos, os três tipos de fontes e o conceito de resposta crítica são descritos, e sao apresentadas sugestôes para a criação e análise de um trocadilho bom ou engraçado. A sátira e a ironia são apresentadas como exemplos de comportamentos controlados por audiências distintas, e poemas de Manuel Bandeira são usados para ilustrar o comportamento satírico. Argumenta-se que fazer humor é aprendido e possivelmente um comportamento adaptativo, na medida que um evento pode ser menos estressante se levado com um senso de humor.
\end{abstract}

Palavras-chave: humor, comportamento verbal, controle múltiplo

ABSTRACT

The current article presents Skinner's (1957) formulation regarding the variables responsible for what is known as humor, with examples related to the Brazilian culture and literature. The behavior responsible for producing humoristic effects upon the listener is understood as being multiply controlled. This behavior is analyzed through its products such as texts and samples of spoken language in which it is possible to make inferences regarding the conditions under which the behavior occurred. Puns and jokes are examples of multiple control given that: 1) the strength of a response is a function of more than one variable, a form of convergent multiple control, and 2) one variable can affect the strength of several responses, a form of divergent multiple control. Multiple control may involve one word or phrase under control of multiple variables, or sources, at the same time. The word or phrase is called critical response, and the controlling variables; main thematic source, secondary source, and carrier source. Through different examples, the three types of sources are described, as well as guidelines for creating a pun that is

1 Endereço para correspondência: Maria Martha Costa Hübner, R. João Avelino Pinho Melão, 120 - ap. 72, Morumbi - São Paulo- SP - Cep: $05659-010$. E-mail: martha@hubner.org.br 
good or funny. Satire and irony are presented as examples of behaviors controlled by distinct audiences, and poems by Manuel Bandeira are presented as examples of satirical behavior. It is argued that being humorous is learned and possibly an adaptive behavior in that an event may be less stressful if it is taken with some "sense of humor".

Key words: humor, verbal behavior, multiple control

Fazer piadas é um comportamento freqüente na cultura brasileira. Comumente diz-se que, mesmo diante de uma tragédia coletiva, o brasileiro faz, no dia seguinte, uma piada sobre o ocorrido.

Para a Análise do Comportamento, fazer humor é um exemplo de comportamento verbal. Tal formulação foi apresentada por Skinner (1957) no livro Verbal Behavior, traduzido para o português sob o título OComportamento Verbal (1978), em que um exercício de interpretação do autor permitiu identificar pistas acerca de um conjunto de variáveis que controlam vários tipos de operantes verbais, além daquelas responsáveis pelo que chamamos de comportamento humorístico.

Entendido como um exemplo de controle múltiplo, como deverá ficar claro adiante, o comportamento de produzir efeitos humorísticos sobre o ouvinte é analisado extensivamente por Skinner através de produtos do comportamento verbal, como textos (de literatura, por exemplo) e amostras de linguagem falada, em que é possível fazer inferências a respeito da história de reforçamento que gerou o produto observado. Assim, amostras de comportamento verbal humorístico já existentes são interpretadas a partir do conceito de controle múltiplo.

A leitura de Verbal Behavior (1957) é, por vezes, difícil e os exemplos de humor são, obviamente, oriundos da língua inglesa, o que torna menor a probabilidade de que o leitor fique, enquanto audiência brasileira, sob controle das mesmas variáveis explicativas das ilustrações sobre humor apresentadas pelo autor.

Neste sentido, o presente texto pretende apresentar a formulação de Skinner (1957) a respeito das variáveis responsáveis pelo comportamento humorístico, com exemplos de nossa literatura e cultura, para que a análise comportamental do humor, com os requintes da análise skinneriana, possa ser mais amplamente conhecida e compreendida no contexto brasileiro.

\section{CONTROLE PELA AUDIÊNCIA}

O comportamento de fazer humor é freqüentemente controlado por múltiplas variáveis ambientais, sendo uma delas a audiência. Na maioria dos casos, comportamento verbal ocorre na presença de um ouvinte que tende a prover conseqüências reforçadoras contingentes ao comportamento do falante. No caso do humor, piadas, por exemplo, são emitidas em maior frequiência, caso exista uma história de reforçamento para sua emissão na presença de determinado(s) ouvinte(s). O ouvinte é, portanto, parte essencial do episódio verbal, não só por funcionar como fonte de reforçamento, mas também por fazer parte da situação na qual o comportamento verbal é observado e reforçado. Dessa forma, o ouvinte funciona também como um estímulo discriminativo, já que sua presença esteve correlacionada com maior probabilidade de reforçamento para o comportamento verbal do falante. Skinner (1957) distingue as funçôes reforçadoras e discriminativas do ouvinte, referindo-se à segunda como o controle pela "audiência” (p. 172).

Assim, a audiência funciona como um estímulo discriminativo, ou seja, como parte de uma ocasião para que o comportamento verbal seja reforçado, portanto, controlando a força ou probabilidade de emissão da resposta. Diferentemente de estímulos discriminativos responsáveis pelo controle de operantes verbais elementares como ecóicos, tactos e intraverbais, a audiência está correlacionada com maior probabilidade de reforçamento para um grupo específico de respostas (Skinner, 1957, p. 173). Audiên- 
cias diferentes controlam subgrupos diferentes de respostas. Um primeiro exemplo de Skinner é o de um indivíduo bilíngüe, cuja probabilidade de emissão de respostas em uma língua aumenta na presença de uma audiência que se comunica em tal língua.

Uma das funções da audiência é a seleção do conteúdo e forma do comportamento verbal, ou seja, o tópico a ser apresentado e a maneira de se fazê-lo. Certas comunidades podem modelar e tornar alta a probabilidade de metáforas, trocadilhos e piadas. A comunidade brasileira pode ser um bom exemplo disto. O riso, por exemplo, é uma das conseqüências reforçadoras que aumenta a probabilidade de ocorrência do episódio verbal subseqüente de alguém contar uma piada.

Há muitas razões pelas quais homens riem, diz Skinner (1957, p. 285): reflexos emocionais, como cócegas e, no campo verbal, porque há surpresa, embaraço, forma atípica (dialetos, sotaques ) e até a vulgarização ou grosseria ("piada suja”). Assim, o inusitado e a surpresa podem fazer rir. Os exemplos abaixo, encontrados na mesa de um bar de uma cidade paulista do interior do estado, podem ilustrar a pertinência desta análise:

Gastei metade do meu dinheiro com mulheres e cerveja....o resto desperdicei.

Depois da tempestade...vem a gripe.

Comecei a beber por causa de uma mulher...e nem tive a oportunidade de lhe agradecer.

Se o leitor rir após cada frase acima é provavelmente porque, antes de tudo, não conhecia previamente estas piadas e porque a segunda parte, após as reticências, é inusitada, ou seja, diferentes do que esperaríamos que alguém dissesse (no caso da primeira e terceira frases), ou porque modifica um provérbio conhecido, com algo pouco esperado, que é, no caso, a retirada do teor metafórico, típico de provérbios, para o teor realista, na segunda frase. Mas a análise pode trazer mais complexidades, quando se apreende o conceito de controle múltiplo no comportamento verbal.

\section{Controle MútTiPLo}

Skinner (1957) lida com dois tipos de controle múltiplo. O primeiro tratamento de controle múltiplo ou causação múltipla aparece quando se discute o controle exercido pela audiência como um estímulo discriminativo. Uma segunda forma de controle múltiplo aparece quando operantes verbais que são estabelecidos separadamente combinam-se em uma ocasião específica. Evidências de controle múltiplo aparecem em amostras da linguagem falada, como em trocadilhos e piadas.

Trocadilhos e piadas são exemplos de controle múltiplo na medida que: 1) a força de uma determinada resposta é função de mais de uma variável, ou seja, uma forma de controle múltiplo convergente; 2) uma única variável geralmente afeta mais de uma resposta, ou seja, uma forma de controle múltiplo divergente. No caso de a força de uma determinada resposta ser função de mais de uma variável (controle convergente), tem-se o seguinte exemplo:

- É a mãe!...

A frase anterior pode ser analisada como um tacto, já que a forma da resposta pode estar sob controle de um estímulo não verbal ${ }^{2}$, ou seja, um objeto ou evento (ou propriedade de um objeto ou evento). "É a mãe!" seria um tacto no caso da frase estar sob controle da presença da mãe de alguém. Tal frase pode também ser classificada como um intraverbal, já que a forma ou topografia da resposta pode estar sendo controlada por um estímulo verbal com a qual não mantém uma correspondência ponto a ponto, ou seja, partes ou subdivisōes do estímulo verbal não controlam diretamente partes ou subdivisões da resposta verbal, como é o caso do comportamento ecóico (estímulo e resposta são fisicamente similares). "Éa mãe!”, neste caso, seria um intraverbal de xingamento, em res-

2 Um estímulo verbal pode ser definido como o produto do comportamento/resposta verbal de A funcionando como um estímulo discriminativo para o comportamento verbal de B. 
posta a um tacto de outro falante, no trânsito difícil da cidade de São Paulo:

- Você é um barbeiro no volante!

- É a mãe!...

Um outro exemplo de controle múltiplo no comportamento verbal em que a força de uma determinada resposta é função de mais de uma variável (controle convergente) é a emissão da palavra "manga", que pode ser evocada como um tacto na presença da fruta ou na presença da parte de uma camisa. Veja que a palavra manga poderia fazer parte de um trocadilho, caso a fruta e a parte da camisa estivessem presentes ao mesmo tempo no momento da ocorrência da resposta. É quando variáveis controladoras da mesma resposta ocorrem ao mesmo tempo que o trocadilho pode ser identificado.

No segundo tipo de controle múltiplo, uma única variável usualmente afeta mais de uma resposta (controle divergente). Skinner dá o exemplo do animal cão, que pode evocar a resposta "cachorro" ou "cão" ou " au-au", em se tratando de crianças pequenas. Assim, um mesmo animal (o cão) evoca múltiplas respostas.

Um tipo de piada comum em nossa cultura também pode ilustrar esse tipo de controle múltiplo: um acidente - a morte de Ayrton Senna, gera as homenagens póstumas e... a piada "O que é um pontinho amarelo no céu?...". Típico da cultura brasileira. Dito de outra forma (e já fazendo aqui um jogo de palavras), "a mesma coisa pode ser dita de várias maneiras", em que "mesma coisa” se refere a um conjunto comum de variáveis e "várias maneiras" a um grupo temático de respostas.

O eufemismo ilustra este tipo de controle múltiplo em que "a mesma coisa pode ser dita de várias maneiras". A resposta eufêmica envolve duas variáveis, presentes ao mesmo tempo, uma que aumenta a freqüência de uma classe de respostas e outra que diminui alguns membros da mesma classe. Por exemplo, quando uma de duas respostas disponível é passível de punição, como, por exemplo, usar o termo " morto" na presença da esposa do indivíduo que morreu, é possível que a presença da esposa reduza a probabilidade da emissão desta resposta, para dar lu- gar ao eufemismo "descansou". Skinner (1957) discute os atos falhos, por exemplo, como formas de eufemismo. Em seu exemplo, um indivíduo chama uma ex-namorada, que se casou com outro, pelo seu nome de solteira, porque o sobrenome do marido é aversivo para ele.

\section{OHUMOR COMOEXEMPLO DE CONTROLE MÚLTIPLO}

Como discutido anteriormente, nos trocadilhos (ou jogo de palavras), geralmente com efeitos humorísticos sobre o ouvinte, o controle múltiplo envolve uma palavra ou frase que está sob controle de pelo menos duas variáveis, ou "fontes" ao mesmo tempo (Skinner, 1957). A palavra ou frase é denominada resposta crítica e as variáveis controladoras são denominadas fontes, que podem ser dos seguintes tipos: fontes temáticas principais, secundárias e fontes transportadoras. Através de um exemplo, os três tipos de fontes e o conceito de resposta crítica poderão ser contextualmente compreendidos.

E avisa o Lula que o povo tá com borsite. Dor no borso. (José Simão, Folha de São Paulo, 15 de maio de 2003).

No trocadilho acima, a resposta crítica é "borsite", referindo-se ao termo médico "bursite", mal que incomodou o presidente brasileiro Luís Inácio Lula da Silva, na época em que o humorista publicou a frase acima. Esta doença do presidente é, portanto, a fonte temática principal, o tópico abordado, sobre o qual será feito um trocadilho. É o conteúdo que dará sentido ao trocadilho ou jogo de palavras. Tem uma relação direta com a resposta crítica.

A fonte secundária é a formal (que é textual e não temática), e está na construção da palavra "borsite", que tem o som semelhante a "bursite", provocando um reforço auditivo automático (Vaughan \& Michael, 1982).

À fonte principal temática, que é a bursite, doença do presidente, acrescenta-se uma outra fonte temática secundária, que é a "borsite", "dor no borso", lembrando a fala caipira "borso" para "bolso". É esta fonte secundária que faz o inteligente jogo de palavras com a doença do presidente e a dura realidade nacional, provocando o efeito humorístico. 
As fontes secundárias fazem o verdadeiro jogo de palavras. Elas podem ser alteradas sem que o sentido principal da frase se altere. Entretanto, são as fontes secundárias que transformam a frase em um trocadilho. Sem elas, a frase não é interessante, ou engraçada.

A fonte transportadora (carrier source) está relacionada à topografia do estímulo e seus efeitos. Se o estímulo é auditivo (alguém lendo a passagem), a fonte transportadora é ecóica - o ouvinte tende a responder através da repetição daquilo que ouviu. Se a fonte é visual (alguém lendo a passagem), a fonte é textual - o ouvinte tende a ler a passagem. No exemplo anterior, a fonte transportadora foi a visual.

Alguns trocadilhos fazem sentido somente se a fonte for ecóica. Ao perguntar a um amigo em um congresso em Toronto, Canadá, como estava, logo após chegar de viagem, ele respondeu: - "Estou um pouco Toronto da viagem...!" A fonte transportadora foi a ecóica, porque o efeito produzido no ouvinte foi o de ouvir "Toronto" (o nome da cidade), como se estivesse ouvindo "tonto", similaridade ecóica, que cria o trocadilho.

Baseado na análise de Skinner (1957), é possível listar requisitos/sugestôes para a criação e análise de um trocadilho (ou piada) bom ou engraçado ${ }^{3}$ :

1. Não selecione um caso em que não exista fonte secundária. No caso de duas fontes principais, o trocadilho é mais elegante, mas não tão engraçado.

2. Dê informaçôes suficientes para que as fontes de controle (temática e secundária) sejam identificadas como relevantes.

3. Identifique a fonte transportadora - quando a resposta crítica é um homônimo, é importante salientar a relevância da fonte ser textual ou ecóica. 4. Identifique a resposta crítica-essa éa unidade de análise que está sujeita ao controle múltiplo - pode ser uma palavra ou frase. Deve existir pelo menos duas fontes de controle para a resposta crítica e elas devem estar ocorrendo ao mesmo tempo.
5. Identifique a fonte temática principal (FTP). No caso, o controle mais óbvio.

6. Identifique a(s) fonte(s) secundária(s).

7. Garanta que as fontes secundárias sejam intrínsecas à ou importantes na situação descrita no trocadilho/piada; e não uma fonte adicional que serve somente ao propósito de evocar a resposta crítica.

José Simão, após a posse do espanhol de sobrenome Rato, como diretor do FMI, anunciou em sua coluna:

"Arme a ratoeira! Botaram um rato no FMI" (José Simão, Folha de São Paulo, 6 de maio de 2004).

Esse parece ser um bom trocadilho porque atende a todos os requisitos: 1) há uma fonte secundária o rato animal, homônimo do Rato, sobrenome do diretor espanhol recém empossado no FMI; 2) em seu texto, José Simão escreve: “Armem as ratoeiras!.... o espanhol Rato foi empossado diretor do FMI. Puseram um rato no FMI. Agora, em vez de detector de metais, a gente vai ter de botar uma ratoeira no aeroporto. Abaixo o Rato...."; 3) a fonte transportadora é a visual, pois como a resposta crítica (Rato, diretor do FMI) é homônima à fonte secundária (rato, animal), o humorista deu-nos informação visual para diferenciálas, escrevendo a fonte temática principal em letra maiúscula; 4) Rato diretor do FMI é a resposta crítica; 5) a fonte temática principal está identificada: posse de Rato no FMI; 6) as fontes secundárias: rato animal, ratoeira, contêm similaridade formal e temática, gerando reforçamento automático; 7) as fontes secundárias são importantes na situação do trocadilho, pois o FMI, no Brasil, é mal visto, como os que "levam nosso dinheiro" e o rato, animal, é o que rói, gerando um possível intraverbal de que o Rato do FMI, como o rato, vai roer, no caso, o dinheiro brasileiro.

A frase seguinte, seria, na maioria dos casos, considerada como sem graça. Alguém ao se despedir, diz "como um mágico, eu vou desaparecer”. Nesse caso a resposta crítica seria "desaparecer". A fonte temática principal seria

3 Uma versão preliminar dessa lista aparece em Michael, J. (2003). Multiple Control II. Material instrucional não-publicado. Kalamazoo, MI: Western Michigan University. 
a mesma variável que controla frases como "ir embora", "sumir daqui". A fonte secundária é temática - a relação entre "mágico" e "desaparecer". Esse jogo de palavras é ruim, ou sem graça, porque a palavra "mágico" não tem nenhuma relevância com a situação, ela foi inserida no trocadilho somente como fonte/variável adicional para evocar a resposta crítica "desaparecer".

\section{O CONTROLE POR MÚLTIPLAS AUDIÊNCIAS}

O controle por múltiplas audiências ocorre quando uma única resposta verbal causa efeitos distintos sobre audiências distintas, ao mesmo tempo.

Múltiplas audiências controlam alguns tipos de humor, como os "cacos" do teatro, por exemplo, em que uma única resposta verbal causa efeitos distintos sobre audiências distintas: uma fala que tem um efeito no comportamento dos personagens e outro sobre a platéia. Os atores geralmente riem e a platéia, por imitação ou inusitado, acabam por rir também.

A ironia é também um exemplo de controle por múltiplas audiências. Skinner (1957) dá um exemplo de ironia, de um professor que manda notas de agradecimento àqueles que enviam livros de cortesia. $\mathrm{O}$ professor escreve "I shall lose no time in reading the book" [não vou perder tempo para ler seu livro]. Com relação à audiência em que aquele que enviou o livro pertence, a frase é sinônima de "Vou ler o seu livro o mais rapidamente possível", mas para uma outra audiência pode ser sinônimo de: "Não vou gastar meu tempo lendo esse livro".

A sátira é um bom exemplo humorístico de controle por múltiplas audiências. A sátira pode ser considerada uma extensão metafórica se divide propriedades com o estímulo original ou metonímica, se ocorre sob controle de um estímulo que freqüentemente acompanha o estímulo original. Um exemplo de sátira com extensão metafórica é o famoso poema de Manuel Bandeira Os sapos em que ele faz uma crítica ao parnasianismo na literatura, que tem por regra um formalismo na poesia, um culto às rimas ricas, ao convencional e metricamente perfeito. Neste poema, Manuel Bandeira, modernista, satiriza o parnasianismo, chamando os parnasianos de sapos, que "martelam" o que não deveria ser martelado: a poesia.

\section{Os sapos}

Enfunando os papos

Saem da penumbra

Aos pulos, os sapos.

A luz os deslumbra.

O sapo-tanoeiro

Parnasiano aguado,

Diz: - "meu cancioneiro

É bem martelado:

\section{Vêde como primo \\ Em comer os hiatos! \\ Que arte! E nunca rimo \\ Os termos cognatos.

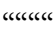 \\ Vai por cinqüenta anos \\ Que lhes dei a norma: \\ Reduzi sem danos \\ A fôrmas a forma.}

\section{Clame a saparia \\ Em críticas céticas: \\ Não há mais poesia, \\ Mas há artes poéticas..." 4}

Para o efeito satírico, as duas audiências são importantes no controle da resposta do falante e do ouvinte. No poema de Manuel Bandeira, as duas audiências são os modernistas e os parnasianos. Em muitos casos, a sátira, pela extensão metafórica e controle por múltiplas audiências, acaba evitando punição de uma das audiências, que desaprovaria a crítica nela embutida. Para que a sátira seja apreciada, o ouvinte deve fazer parte das duas audiências.

4 Os autores agradecem ao professor de Língua Portuguesa Domingos Pozzetti Neto pela colaboração na seleção dos poemas de Manuel Bandeira. 
Assim, no poema de Bandeira, temos que conhecer o parnasianismo, ainda que em linhas gerais, o seu rigor e tradicionalismo e o caráter ousado dos modernistas, quando comparados a eles.

Nota-se, ainda, no poema de Bandeira, que há também um bom e elegante jogo de palavras na quarta estrofe entre "fôrmas" (com o acento circunflexo diferencial em vigor em 1958 ) e forma, com duas fontes temáticas principais - a forma e as "fôrmas" do parnasianismo- e secundárias- a similaridade ecóica e visual entre as duas palavras. Neste jogo de palavras, o parnasianismo é satirizado por reduzir a forma de se fazer poesia a "fôrmas", regras rígidas e limitantes, como uma forma de bolo.

Vê-se, abaixo, um exemplo de sátira, com extensão metonímica, em relação à senadora Heloísa Helena, conhecida como a "do contra":

Heloísa Helena no restaurante só pede CONTRAfilé. E ainda vai entrar na marinha para ser $\mathrm{CON}$ TRA-almirante. (José Simão, Folha de São Paulo, 15 de maio de 2003).

\section{O PORQUÊ DO CONTROLE MÚLTIPLO SER DIVERTIDO}

Na maioria dos casos, trocadilhos passíveis de controle múltiplo não são divertidos, caso o estímulo verbal tenha importância prática para o ouvinte. Veja o exemplo:

\section{- Que horas são?}

- Cinco e sessenta

A resposta "cinco e sessenta" é um trocadilho no sentido de ser passível de controle múltiplo, já que é controlado pelo estímulo auditivo "que horas são" (1) como uma variável que aumenta a probabilidade de respostas de se observar/ informar as horas, e (2) como variável que aumenta a probabilidade da resposta "cinco e sessenta", conhecido intraverbal do papai papudo no programa infantil do Bozo, da década de 80. Entretanto, se saber as horas é de importância prática para o ouvinte, o trocadilho será percebido como sem graça.

Aprendemos a nos divertir, a rir, ao sermos expostos a situações nas quais pessoas estão, em um certo sentido, "brincando", por não haver, na verdade, nenhuma conseqüência prática. No exemplo de José Simão, no qual Heloísa Helena só pede 'CONTRA-file’”, o ouvinte que ri identifica a situação irreal e não espera encontrar a senadora pedindo contra-filé no restaurante. A reação à sátira não é em termos práticos. Estas situaçōes de "brincadeira” contêm estímulos como expressões faciais, tons de voz, etc., que estão correlacionados com maior probabilidade de reforçamento para comportamentos que se afastam de ou satirizam problemas cotidianos ou questôes práticas. Nessa história de reforçamento, indivíduos são condicionados a se divertirem quando outros também o fazem. Assim, existe um componente de imitação, na qual somos reforçados a rir quando outros também estão rindo, além de um componente discriminativo, já que a comunidade tende a reforçar diferencialmente "risadas" ou expressões de divertimento, na presença de trocadilhos envolvendo formas específicas de controle múltiplo (que são considerados engraçados pela comunidade). A exposição a diversas formas de controle múltiplo faz, portanto, parte desse condicionamento. O humor ocorre, portanto, quando o controle múltiplo é identificado pelo ouvinte. Alguém que "não entende a piada" é aquele que não identificou as diferentes variáveis de controle da resposta verbal presentes ao mesmo tempo.

\section{FAZER HUMOR É UM COMPORTAMENTO ADAPTATIVO?}

O rir é uma resposta relaxante muscular. Skinner (1957) diz que um evento é menos irritante se levado com um senso de humor. Manuel Bandeira (1958) também diz que viver com humor é bem melhor.

Um exemplo de galhardia e de bom humor, em uma situação aversiva, pode ser identificado a seguir, em uma descrição apresentada por Skinner: uma senhora, que havia ajudado Napoleão O Terceiro quando ele estava no exílio na Inglaterra, foi virtualmente ignorada por ele quando ele retornou ao seu trono na França. Em um encontro casual, Napoleão perguntou-lhe:

- Restez-vous longtemps à Paris? (- Ficará muito tempo em Paris?)

E ela respondeu, provavelmente com um leve sor- 
riso sarcástico nos lábios:

Et vous, sire? (- E Vossa Excelência?)

A resposta inteligente e bem humorada teve uma clara função: a de reduzir a probabilidade da crítica ser punida. Neste sentido, fazer humor pode evitar punição e reduzir os efeitos colaterais desagradáveis de eventos aversivos.

Talvez, também por isso, o brasileiro faça tanto humor....Uma estratégia de sobrevivência em tempos difíceis? Um refugiado de um sistema totalitário disse em um programa de tv: "Na época da ditadura, só tínhamos o humor..." Bandeira (1958) é tão convicto do valor adaptativo do humor, que o coloca como um dos "prérequisitos para se conquistar um lugar no céu":

Irene preta

Irene boa

Irene sempre de bom humor

Imagino Irene entrando no céu:

- Licença, meu branco!

E São Pedro bonachão:

- Entra, Irene, você não precisa pedir licença.

(Manuel Bandeira, 1958)

\section{CONSIDERAÇŌES FINAIS}

O presente artigo apresentou a formulação de Skinner para as variáveis controladoras do comportamento humorístico, com exemplos de nossa literatura e cultura, bus- cando, com isso, divulgar a análise comportamental de um operante freqüente na cultura brasileira. Amostras do comportamento verbal humorístico já existentes em textos brasileiros foram interpretadas a partir do conceito de controle múltiplo, com o objetivo de ampliar a compreensão deste importante conceito para o comportamento verbal. Embora o texto permaneça no nível de um exercício de interpretação, o que é um limite para a sua imediata aplicação, as possibilidades de desenvolvimento de estudos para a verificação da plausibilidade das interpretaçóes aqui apontadas existem, na medida que as classes de respostas humorísticas e as variáveis de controle aqui sugeridas são facilmente identificáveis e passíveis de serem manipuladas em condiçôes experimentais. Além disso, a listagem dos requisitos para a criação de trocadilhos engraçados oferecida no presente artigo dá algumas pistas de como o comportamento humorístico é ensinado, o que pode se mostrar relevante como parte de um programa de ensino de habilidades sociais ou de enfrentamento de situações inevitavelmente aversivas.

\section{REFERÊNCIAS}

Bandeira, M. (1958). Poesia e Prosa. José Aguillar: Rio de Janeiro.

Skinner, B. F. (1957). Verbal behavior. New York: Appleton-Century-Crofts.

Vaughan, M. E., \& Michael, J. (1982). Automatic reinforcement: An important but ignored concept. Behaviorism, 10, 217-227. 